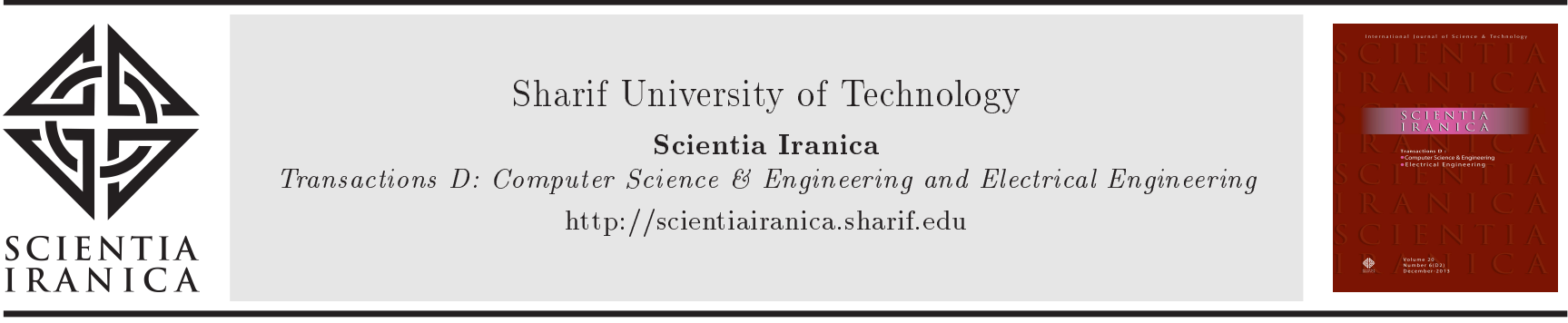

\title{
Reliability evaluation for power systems containing ocean thermal energy conversion power plants
}

\author{
K. Nasiriani ${ }^{\mathrm{a}}$, A. Ghaedi ${ }^{\mathrm{b}, *}$, and M. Nafar ${ }^{\mathrm{a}}$ \\ a. Department of Electrical Engineering, Marvdasht Branch, Islamic Azad University, Marvdasht, Iran. \\ b. Department of Electrical Engineering, Dariun Branch, Islamic Azad University, Dariun, P.O. Box 7145168598, Iran. \\ Received 30 November 2019; received in revised form 25 May 2020; accepted 6 July 2020
}

\section{KEYWORDS}

Adequacy;

Clustering;

Ocean thermal energy

conversion;

Reliability;

Conditional value at

risk.

\begin{abstract}
Recently, renewable power plants utilize clean and sustainable resources for electricity generation. The Ocean Thermal Energy Conversion (OTEC) system uses ocean surface water as a high-temperature source and the water at a depth of the ocean as a low-temperature source. The difference between these temperatures is $20^{\circ} \mathrm{C}$ or greater, and the working fluid with a low boiling point can be used for electricity generation. In a closed-cycle OTEC system, the working fluid through a thermodynamic cycle based on the Rankine cycle can rotate the turbine and generate electricity. Due to the ocean surface temperature variation, the output power of the OTEC system changes and yields numerous states concerning the generated power of this plant. Thus, for integrating the OTEC systems with the power system, many aspects of power system including reliability may be affected and thus, new approaches must be developed for investigation of these effects. In this paper, the reliability of the power system containing the OTEC system based on the multi-state reliability model and the conditional value at risk concept is evaluated and the valuable indices used for generation expansion planning of the power system are calculated.
\end{abstract}

(C) 2022 Sharif University of Technology. All rights reserved.

\section{Introduction}

In recent years, renewable energy resources, especially wind, solar, and ocean, have been increasingly utilized instead of fuel-based power plants for electrical power generation in modern power systems. The growing interest in use of renewable energy resources results from different problems associated with fossil fuels such as sudden increase in their prices, non-sustainable nature of these resources, and greenhouse gas emission that result in climate change, earth warming, and other environmental effects. Among renewable resources,

*. Corresponding author. Fax: 07132746390

E-mail address: amir_ghaedi_63@yahoo.com (A. Ghaedi)

doi: $10.24200 /$ sci. 2020.54805 .3927 because of the vast area of the oceans, different kinds of ocean energies such as wave, tidal, and ocean thermal energies can play a vital role in the generation sector of future power systems. The surface area of the oceans is very large and upon receiving solar radiation, Ocean Thermal Energy Conversion (OTEC) systems can be used for supplying significant consumers in the world. To integrate the OTEC system into power grids, many studies were done in the past. In [1], the principles and equations associated with the generated power calculation for an OTEC system were elaborated. In this paper, from the numerical analysis, it was concluded that the overall efficiency of the system was $3.97 \%$. In [2], history, different types, different applications, and environmental impacts of OTEC technology were given. In [3], organic isobutene was employed as a working fluid in a $110 \mathrm{MW}$ on-shore, closed-cycle 
OTEC power plant. In this paper, power generation process, energy calculation, and cost analysis were studied. In [4], different types of OTEC systems, environmental considerations, and economics of different applications of OTEC including fresh water generation, refrigeration and air conditioning, Mari culture, agriculture, and energy carriers were illustrated. In [5], the performance evaluation for and optimal design of a 50 MW OTEC power plant based on the Rankine cycle with R-22 as the working fluid were conducted. In [6], the sensitivity analysis of a closed-cycle OTEC power plant was performed. In addition, the effects of variations in warm and cold water temperatures, warm and cold water pipe diameters, warm and cold water velocity in pipes, and evaporator and condenser working temperatures on the net generated power and efficiency of the system were analyzed. In [7], the genetic algorithm as a multi-objective optimization problem was solved and optimal designs of OTEC power plants with 10, 50, and $100 \mathrm{MW}$ capacities were achieved. In this study, the warm sea water velocity, warm water pipe diameter, temperatures of sea water, and condenser and evaporator were considered as optimization parameters. In [8], it was suggested that the discharge water of nuclear or fossil power plants could be used as a high-temperature source in the OTEC power plant instead of ocean surface water. Therefore, the application of this method helped mitigate the environmental impact of power plant discharge. In [9], the combination of OTEC system and solar energy in an organic Rankine cycle to generate electric power was studied and the effects of variation in different effective parameters including turbine inlet temperature, turbine exit quality, turbine inlet pressure, and condenser exit temperature on system efficiency were investigated. In [10], the potential of South China Sea encompassing a large area over $3.5 \mathrm{~km}^{2}$ with a surface temperature of around 24 to $30^{\circ} \mathrm{C}$ throughout the year to generate electric power using the OTEC system was investigated and it was concluded that about $0.5 \mathrm{TW}$ electric power could be generated with consideration of Carnot efficiency. In [11], low efficiency and high energy consumption were considered as the two main drawbacks of the OTEC systems and therefore, in this paper, wave, solar, and OTEC systems were integrated to construct a water-electricity cogeneration system as well as to improve the efficiency and reduce energy consumption of this system. In [12], technoeconomic characteristics of some renewable resources including wave, tidal, geothermal, and ocean thermal were studied. The global capacity of ocean thermal energy and its long-term costs were estimated to be $5000 \mathrm{GW}$ and $0.1-0.18 \$ / \mathrm{kWh}$, respectively. The generated power of an OTEC system is dependent on the temperature of ocean waters and due to the variation in these temperatures throughout the year, the generated power of OTEC power plants varies too, thus affecting different aspects of integration of OTEC power plants in the power system such as reliability indices. Variation in the output power of the renewable resources including wind, solar, tidal, wave, etc. is the main drawback of these clean energies. Thus, many studies have been devoted to studying the effects of these resources on different aspects of power systems [13-20]. The reliability evaluation for OTEC systems has not been performed so far and in this regard, the research papers associated to the reliability assessment for other renewable resources such as wind, solar, wave, tidal, and so on can be reviewed and utilized. In [21], sequential Monte Carlo simulation technique and fuzzy theory were employed to calculate the reliability indices (based on the well-being approach) of a system with a high penetration of wind resources considering the impacts of demand response program. In [22], a novel generation rescheduling algorithm was applied to enhance the reliability of a power system containing high renewable energy penetration. In [23], Monte Carlo simulation approach based on the cross-entropy and Copula techniques was utilized for investigating the adequacy of the generation system containing a high share of wind power considering the correlation between wind farms. In [24], reliability evaluation for a distribution network containing photovoltaic systems considering the time-varying failure rate of conventional power equipment, variation in radiation intensity, and failure and degradation of photovoltaic modules was performed. In [25], reliability assessment for a distribution network containing renewable resources and parking lots was performed using the non-sequential Monte Carlo simulation approach and it was concluded that parking lots could improve the reliability of renewable-based distribution networks. In [26], a new robust and easy-to-use model was developed for solar radiation simulation that could be used for assessing the reliability of power systems containing solar generation systems. In [27], a new approach was proposed to evaluate the reliability of wind farms considering the correlation between wind speed and wind turbine reliability. In [28], a reliability model was constructed for wind farms considering wind variability, failure of turbines, and correlation between turbine outputs. The proposed model includes both probability and frequency distribution of the power output associated to the wind farms. In [29], the optimal layout of an offshore wind farm based on the constant number of wind turbines and a constant area of coverage was determined using the mixed integer linear programming method. This optimal layout was determined through maximization of output power, minimization of the cable cost, and maximization of the reliability. In [30], a stochastic multi-objective model employed to optimally exchange the energy of renewable-based 
microgrids under risk-based strategies was developed. In the objective function, the economic and reliability factors were considered and to address the uncertainty nature associated to the loads and renewable resources, three various risk-based strategies based on the Conditional Value at Risk (CVaR) approach were utilized. In [31], the Value at Risk ( VaR) and CVaR approaches were employed to measure the long-term operational reserve of the renewable-based power system. In this paper, to analyze the medium- and long-term operation studies on the power system in terms of the variability and uncertainty of the renewable generation capacity, a risk-based technique was proposed to achieve more robust and flexible generating configurations. In [32], a robust optimization approach based on the CVaR was proposed to perform the unit commitment in a market with probabilistic offers. This paper proposed a risk-aware market clearing strategy to consider the uncertainty nature of wind power and other stochastic resources by accepting probabilistic offers based on the conditional value at risk in a power system containing large-scale renewable resources. In [33], the optimal control of energy storage in a microgrid was performed by minimizing the conditional value at risk. In this paper, two methods based on the concept of rolling horizon control were proposed to control an energy storage system optimally in a grid-connected microgrid considering the uncertainty of demand and electricity pricing. The control was performed based on the scenario-based stochastic CVaR optimization, and in the cost function, electricity usage cost, operation cost of the battery, and grid signal smoothing objectives were taken into account. In [34], capacity configuration optimization was carried out for stand-alone microgrids upon considering the uncertainties of wind and solar resources. In this paper, a microgrid including wind, photovoltaic, diesel, and battery was considered and a stochastic optimization model based on CVaR was proposed to take into account the operation risk of a microgrid arising from uncertainties of wind and solar resources. As mentioned earlier, reliability assessment for OTEC systems has not been studied so far and thus, in this regard, the reliability evaluation for a power system containing OTEC power plants has been performed in this paper for the first time. For this purpose, a reliability model was constructed for OTEC power plants by considering both failure rates of the composed components and variation in the generated power arising from the uncertain nature of ocean water temperature. The failure rate of the OTEC system varied with time and thus, the average failure rate was calculated to be used in the associated model. Based on this reliability model, a multi-state generation unit was obtained and utilized for studying the adequacy of a power system containing OTEC power plants. The Fuzzy C-Means (FCM) clustering method and Xie and
Beni (XB) index were implemented for determining appropriate states of this reliability model. To study the effect of the uncertainty associated to the ocean temperature variation, the reliability indices based on the CVaR were calculated. Thus, the contributions of this paper are given below:

- An analytical multi-state model that considers both failure of the composed components and variation in the generated power arising from variation in the temperature of ocean surface is developed for OTEC systems;

- To reduce the number of states in the reliability model of OTEC systems, the FCM clustering technique is utilized;

- To determine the optimum number of states in the reliability model of OTEC system, the $\mathrm{XB}$ index is calculated;

- A large-scale OTEC system is integrated into the power system and the adequacy indices are calculated;

- To consider the uncertainty of ocean surface temperature, the adequacy indices of the power system in the presence of OTEC system are calculated based on the concept of CVaR.

Based on the objectives, this paper is organized as follows: the structure, principle, and different types of the OTEC systems are illustrated in the second part. In the third part, related equations associated to the power generated by OTEC power plants are presented and a suitable working fluid is selected among ammonia, R-22, and R-134a for use in the OTEC power plant. The proposed multi-state reliability model of OTEC power plants is developed in the first subsection of the fourth section. In the second subsection, the CVaR concept to model the uncertainty of ocean surface temperature is introduced and in the third subsection, the proposed technique is introduced to evaluate the adequacy of a power system containing OTEC power plants based on the multi-state model and CVaR. The technique to study the effect of the transmission network on the reliability of the renewable-based power system is introduced in the fourth subsection. In the fifth section, the numerical results associated with Roy Billinton Test System (RBTS) and IEEE Reliability Test System (IEEE-RTS) as two well-known test systems considering the effects of OTEC power plants based on the multi-state reliability model and CVaR concept are investigated. The conclusion of this study is summarized in the sixth section.

\section{OTEC systems}

Greenhouse gas emission derived from burning fossil fuels results in climate change and global warming. 


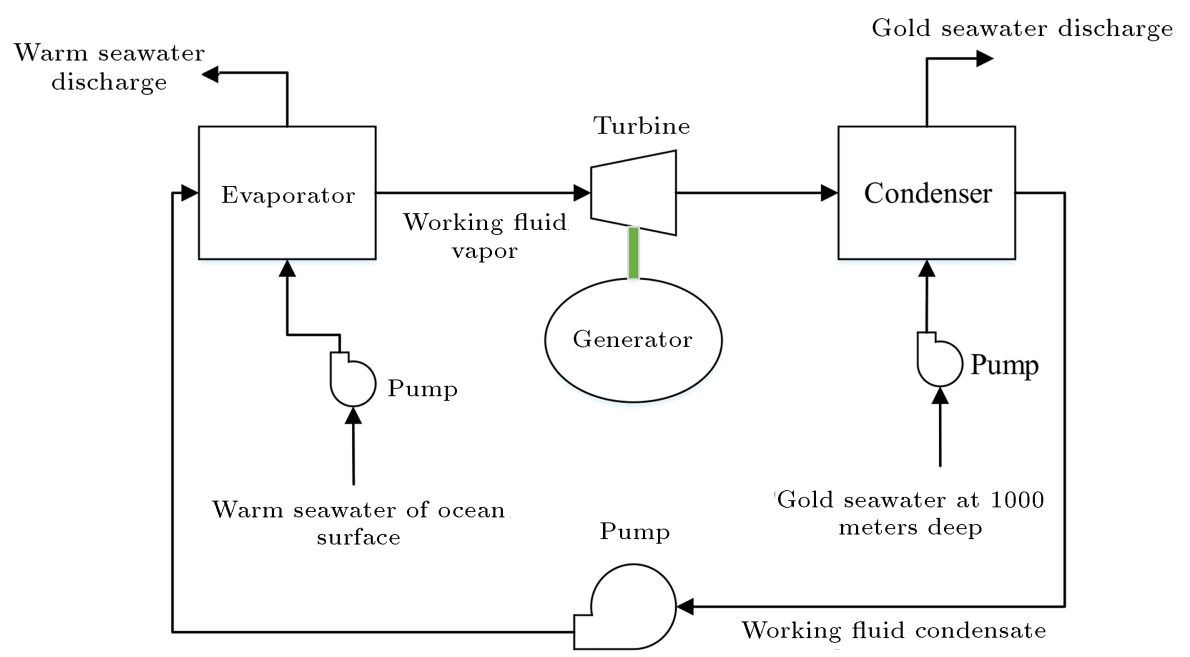

Figure 1. The structure of the closed-cycle ocean thermal energy conversion power plant.

In light of these effects, global organizations should enact certain laws to reduce the use of fossil fuels on a global scale. So, many countries ought to add some incentives and encouraging measures to their generation expansion planning for the greater use of renewable resources to generate electric power. OTEC systems use one of these renewable energies from the sun. The temperature of oceans with a very large area may increase up to $20-30^{\circ} \mathrm{C}$ which is optimal for receiving thermal energy from the sun. The temperature of the water at a depth of $1000 \mathrm{~m}$ is about $4-5^{\circ} \mathrm{C}$ and because of this difference between temperatures of water on the surface and the water at a depth of $1000 \mathrm{~m}$, a thermodynamic Rankine cycle is applied to electric power generation.

\subsection{Different types of OTEC systems}

Three types of OTEC power plants including closed cycle, open cycle, and hybrid cycle can be constructed. In an open-cycle OTEC power plant, sea water is used as working fluid and warm sea water (water in the surface) is pumped into a flash evaporator with 0.03 bar pressure which causes the water to boil at a temperature of $22^{\circ} \mathrm{C}$. The resulting steam expands through a low-pressure turbine that is connected to a synchronous generator for electric power generation. Then, the steam passes through a condenser and it is derived from the cold seawater at depths of the ocean to condense the steam into desalinized water. In a closed-cycle OTEC power plant, a low boiling point liquid such as ammonia, R-22, R-134a, or another type of refrigerant is used as the working fluid in a Rankine cycle. The heat from warm seawater of ocean surface flowing through an evaporator causes the working fluid to vaporize. Then, the vapor expands through a turbine and generates the electric power using the generator connected to the turbine. The steam flows into a condenser and the cold seawater condenses it into a liquid. A hybrid-cycle OTEC power plant is a combination of both closed and open cycles. In this system, the fresh water is initially flashed into steam, similar to the closed-cycle approach that takes place in a vacuum vessel. In the same vessel, ammonia or another working fluid is evaporated through heat exchange using the warm water from the ocean surface. The working fluid is then physically mixed with the warm seawater in a two-phase, twosubstance mixture. The evaporated working fluid is then separated from the steam/water, re-condensed, and re-introduced into the closed-loop cycle. The phase change of the water/working fluid vapor rotates a turbine generating the electric power.

\subsection{The structure of the closed-cycle OTEC system}

In this paper, the closed-cycle OTEC power plant is studied and the reliability model of this plant is developed. Figure 1 presents the structure and composed components of this system. As can be seen in the figure, in closed-cycle OTEC systems, the working fluid is pumped and then, its temperature in a heat exchanger exposed to the surface water is increased and converted into vapor. The resulting vapor turns the turbine on and consequently, the generator becomes connected to the turbine, thus producing electric power. The output vapor of the turbine is converted into liquid in the heat exchanger using the cold seawater which is pumped from the $1000 \mathrm{~m}$ deep.

\section{Generated power of closed-cycle OTEC systems}

In this section, different thermodynamic equations associated to the Rankine cycle are evaluated and the generated power of a closed-cycle OTEC power plant is determined. 


\subsection{Thermodynamic relations of generated power}

The temperature-entropy (T-S) diagram of Rankine cycle associated to a closed-cycle OTEC system is presented in Figure 2. The entropy $\left(\mathrm{kJ} /\left(\mathrm{kg}^{\circ} \mathrm{K}\right)\right)$ is a thermodynamic quantity to present the unavailability of a system's thermal energy for conversion into mechanical work, often interpreted as the degree of disorder or randomness in the system. The pure power generation of an OTEC power plant can be calculated as follows:

$$
P_{N}=P_{G}-P_{W F P}-P_{W W P}-P_{C W P},
$$

where $P_{G}$ is the generated power of the generator and $P_{W F P}, P_{W W P}$, and $P_{C W P}$ are the power required for pumping working fluid, warm water, and cold water, respectively. The generated power of the generator connected to the turbine can be calculated as follows:

$$
P_{G}=\dot{m}_{W F} \eta_{G} \eta_{T}\left(h_{1}-h_{2}\right),
$$

where $\dot{m}_{W F}$ is mass flow rate of the working fluid (kg/s), $\eta_{G}$ and $\eta_{T}$ are generator and turbine efficiencies, and $h_{1}$ and $h_{2}$ are the enthalpies of evaporator outlet (turbine inlet) and condenser inlet (turbine outlet), respectively $(\mathrm{J} / \mathrm{kg})$. The enthalpy is a thermodynamic quantity equivalent to the total heat content of a system. It is equal to the internal energy of the system plus the product of pressure and volume. For power generation in the Rankine cycle, the turbine expands in the adiabatic process (constant entropy).

The power required for pumping working fluid, warm water, and cold water is determined as follows:

$$
\begin{aligned}
& P_{W F P}=\dot{m}_{W F} g h_{W F} / \eta_{W F P}, \\
& P_{W W P}=\dot{m}_{W W} g h_{W W} / \eta_{W W P},
\end{aligned}
$$

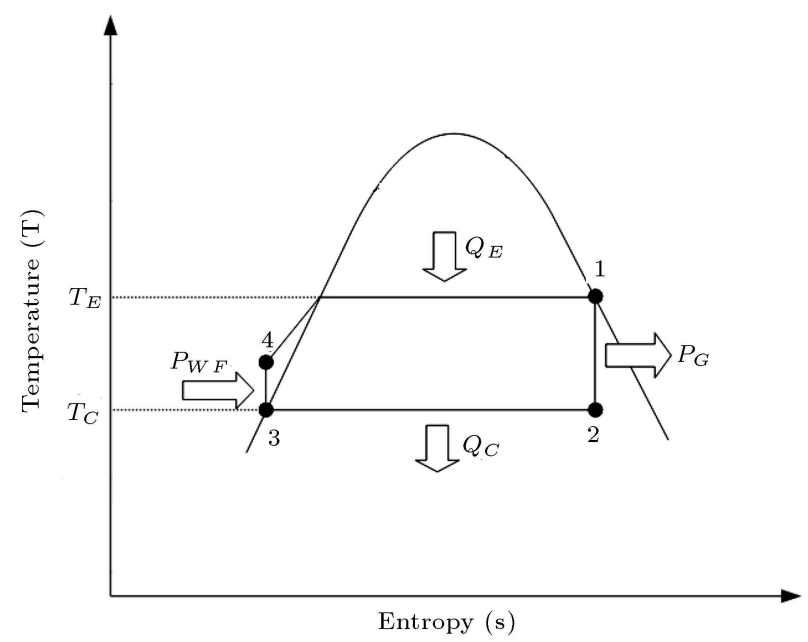

Figure 2. The temperature-entropy (T-S) diagram of the closed-cycle ocean thermal energy conversion power plant.

$$
P_{C W P}=\dot{m}_{C W} g h_{C W} / \eta_{C W P}
$$

where $\dot{m}_{W F}, \dot{m}_{W W}$, and $\dot{m}_{C W}$ are mass flow rates of working fluid, warm water (ocean surface water), and cold water (water at $1000 \mathrm{~m}$ deep); $g$ is acceleration of gravity $\left(\mathrm{m} / \mathrm{s}^{2}\right) ; h_{W F}, h_{W W}$, and $h_{C W}$ are total pressure difference (arisen from the difference in the height of the plant or friction of the pipes) associated to the working fluid, warm seawater, and cold seawater; $\eta_{W F P}, \eta_{W W P}$, and $\eta_{C W P}$ are efficiencies of pumping of working fluid, warm water, and cold water. The heat transfer rates $(\mathrm{J} / \mathrm{s})$ for the evaporator $\left(Q_{E}\right)$ and the condenser $\left(Q_{C}\right)$ are calculated as follows:

$$
\begin{aligned}
& Q_{E}=\dot{m}_{W F}\left(h_{1}-h_{4}\right), \\
& Q_{C}=\dot{m}_{W F}\left(h_{2}-h_{3}\right),
\end{aligned}
$$

where $h_{3}$ and $h_{4}$ are the enthalpies associated to the inlet and outlet of the working fluid pump, respectively. In addition to Eq. (3), the power that is required for pumping working fluid can be calculated as follows:

$$
P_{W F P}=\dot{m}_{W F}\left(h_{4}-h_{3}\right) \text {. }
$$

In this part, three working fluids including ammonia, R-22, and R-134a are considered and the generated power of these working fluids in a closed-cycle OTEC power plant with the same working fluid mass flow rate is calculated. Thermodynamic properties of saturated ammonia, R-22, and R-134a were illustrated in [35]. Table 1 shows the thermodynamic properties of ammonia at temperatures between 20 and $26^{\circ} \mathrm{C}$ including temperature, pressure, specific volume, enthalpy, and entropy. It is assumed that a closed-cycle OTEC power plant is constructed in Hawaii. The hour-to-hour data associated to the temperature of ocean surface in this region for the year 2016 are given in Figure 3.

For calculating the generated power of the power plant at each hour, the temperatures of warm and cold waters are considered as the temperature of the saturated vapor in state 1 and the temperature of saturated liquid in state 3 of Figure 2, respectively.

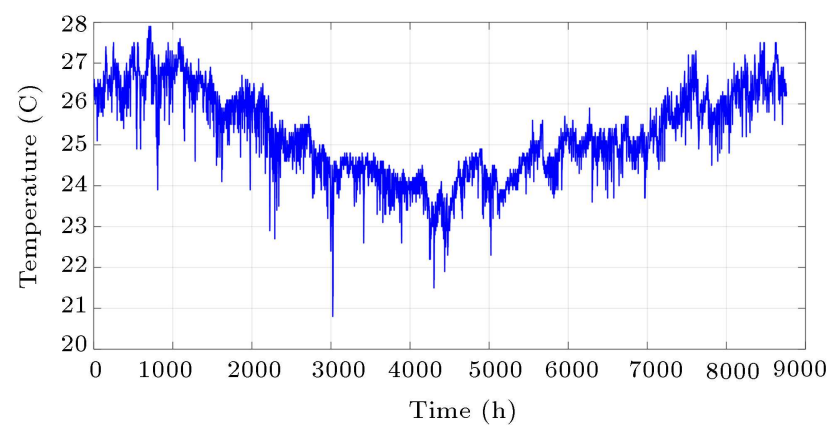

Figure 3. The temperature of ocean surface in Hawaii in 2016 . 
Table 1. Thermodynamic properties of saturated ammonia [35].

\begin{tabular}{ccccc}
\hline Temp. $\left({ }^{\circ} \mathbf{C}\right)$ & $\mathbf{2 0}$ & $\mathbf{2 2}$ & $\mathbf{2 4}$ & $\mathbf{2 6}$ \\
\hline Pressure $(\mathrm{kPa})$ & 857.6 & 913.8 & 972.7 & 1034.5 \\
Spec. vol. $v_{f}\left(\mathrm{~m}^{3} / \mathrm{kg}\right)$ & 0.001638 & 0.001646 & 0.001655 & 0.001663 \\
Spec. vol. $v_{f g}\left(\mathrm{~m}^{3} / \mathrm{kg}\right)$ & 0.1476 & 0.1387 & 0.1304 & 0.1227 \\
Spec. vol. $v_{g}\left(\mathrm{~m}^{3} / \mathrm{kg}\right)$ & 0.1492 & 0.1403 & 0.132 & 0.1243 \\
Enthalpy $h_{f}(\mathrm{~kJ} / \mathrm{kg})$ & 294.3 & 303.9 & 313.5 & 323.1 \\
Enthalpy $h_{f g}(\mathrm{~kJ} / \mathrm{kg})$ & 1185.7 & 1177.5 & 1169.2 & 1160.8 \\
Enthalpy $h_{g}(\mathrm{~kJ} / \mathrm{kg})$ & 1479.9 & 1481.3 & 1482.7 & 1483.9 \\
Entropy $s_{f}\left(\mathrm{~kJ} /\left(\mathrm{kg}{ }^{\circ} \mathrm{K}\right)\right.$ & 1.3308 & 1.363 & 1.3951 & 1.4271 \\
Entropy $s_{f g}\left(\mathrm{~kJ} /\left(\mathrm{kg}{ }^{\circ} \mathrm{K}\right)\right.$ & 4.0446 & 3.9894 & 3.9347 & 3.8803 \\
Entropy $s_{g}\left(\mathrm{~kJ} /\left(\mathrm{kg}{ }^{\circ} \mathrm{K}\right)\right.$ & 5.3753 & 5.3524 & 5.3298 & 5.3074 \\
\hline
\end{tabular}

Therefore, according to the thermodynamic table of working fluid [35], the pressure, enthalpy, and entropy of these two states can be obtained. Upon considering state 1 in saturated vapor and state 3 in saturated liquid, in Rankine cycle of Figure $2, h_{3}=h_{f}, s_{3}=s_{f}$, $v_{3}=v_{f}, P_{3}=P_{2}, P_{1}=P_{4}, h_{1}=h_{g}, s_{1}=s_{g}$. The subscripts $f, f g$, and $g$ are used for saturated liquid (a liquid that is about to vaporize), saturated liquidvapor mixture (the state in which the liquid and vapor phases coexist in equilibrium), and saturated vapor (a vapor that is about to condense), respectively. From the adiabatic process of turbine expansion, $s_{1}=s_{2}$. If the state is a mixture of liquid and vapor, the entropy can be determined as follows: $s=s_{f}+x s_{f g}$, where $x$ is the quality and $s_{f}$ and $s_{f g}$ are saturated values listed in [35]. Thus, the quality $(x)$ of state 2 can be calculated as follows:

$$
x=\frac{s_{2}-s_{f}}{s_{f g}}=\frac{s_{1}-s_{3}}{s_{f g}} .
$$

When a substance exists as part liquid and is vaporized in saturation conditions, its quality $(x)$ is defined as the ratio of the mass of the vapor to the total mass of both vapor and liquid. Thus, the enthalpy of state 2 can be calculated as:

$$
h_{2}=h_{f}+x h_{f g}=h_{3}+x h_{f g} .
$$

The required power for pumping working fluid in $\mathrm{kJ} / \mathrm{kg}$ can be calculated as follows:

$$
p_{W F P}=h_{4}-h_{3}=v_{3}\left(P_{4}-P_{3}\right) .
$$
follows:

Thus, the enthalpy of state 4 can be calculated as

$$
h_{4}=h_{3}+p_{W F P} .
$$

Based on the thermodynamic equations of the Rankine cycles (1) to (12), the generated power of a closed-cycle OTEC power plant can be calculated.

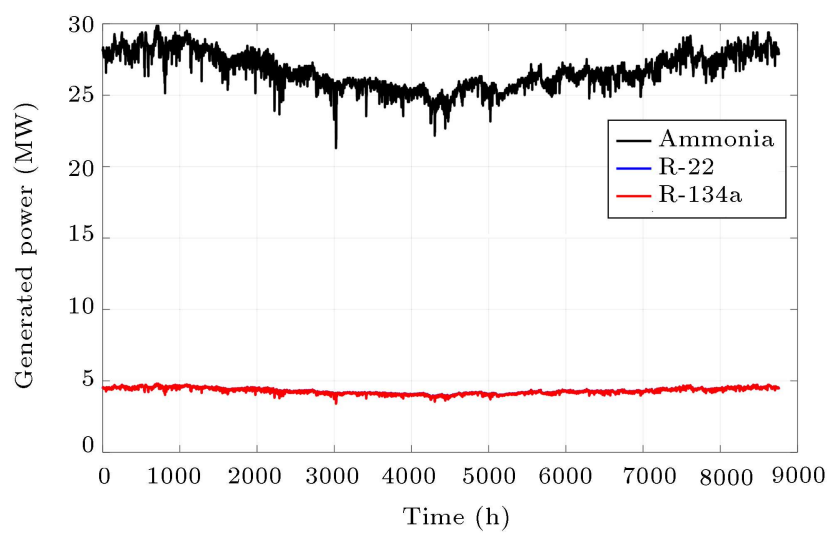

Figure 4. The generated power of ocean thermal energy conversion power plants that utilize ammonia, R-22, and R-134a as working fluids.

\subsection{Comparison of different working fluids}

The generated power of OTEC power plants that use ammonia, R-22, and R-134a as three working fluids in the year 2016 is calculated and presented in Figure 4. As can be seen in the figure, the maximum generated power associated to ammonia is $30 \mathrm{MW}$, while for the other two working fluids, it is about $5 \mathrm{MW}$. Thus, with the same mass flow rate, the OTEC plant that utilizes ammonia can produce the electric power about 6 times more than the OTEC power plant that uses $\mathrm{R}-22$ and R-134a. The power generated by OTEC power plants that use R-22 and R-134a working fluids is approximately the same.

\section{Reliability modeling of OTEC power plants}

In this section, a multi-state reliability model of closedcycle OTEC power plants is developed, which can be used for studying the adequacy of a power system containing these renewable resources. Power system reliability is the ability of a power system to supply the required demand of the consumers and it comprises two aspects: adequacy and security. Adequacy of a 
power system is satisfied when adequate facilities in the generation, transmission, and distribution parts of that power system are available to supply the loads and the security of a power system is the ability of the system to respond to different events such as outage of the generation units or transmission lines and so on. To perform reliability evaluation for power systems, two approaches including analytic and numerical methods are available. The numerical approaches are based on the Monte Carlo simulation and require a huge volume of computation due to numerous repetitions.

\subsection{Reliability modeling of OTEC system}

In this paper, an analytic reliability model of OTEC power plants is introduced that considers both failure of composed components and variation in the generated power. The main components of a closed-cycle OTEC power plant are the main structure, mooring system (for maintaining the main structure and the pipes in the ocean), pipes, turbine, generator, evaporator, condenser, three pumps (for pumping working fluid, warm and cold water), electrical converter, control system, transformer, and cable. With failing of these components, the operation of the system must be stopped and the generated power of the system would be zero. Thus, in terms of reliability, these components are connected in series in the reliability model of the power plant, as can be seen in Figure 5. A twostate (up and down) Marco model, as can be seen in Figure 6, can be used for reliability modeling of each model component seen in Figure 5. In this model, $\lambda$ and $\mu$ are failure and repair rate of the components, respectively [36]. The probabilities associated to up and down state can be determined through Eq. (13):

$$
P_{u p}=\frac{\mu}{\mu+\lambda}, \quad P_{\text {down }}=\frac{\lambda}{\lambda+\mu}
$$

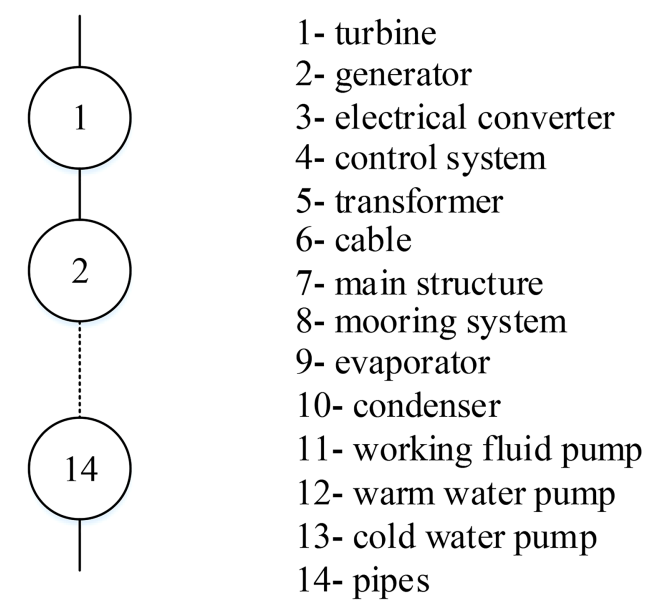

Figure 5. Series connection of the composed components of closed cycle ocean thermal energy conversion power plants in the reliability model.

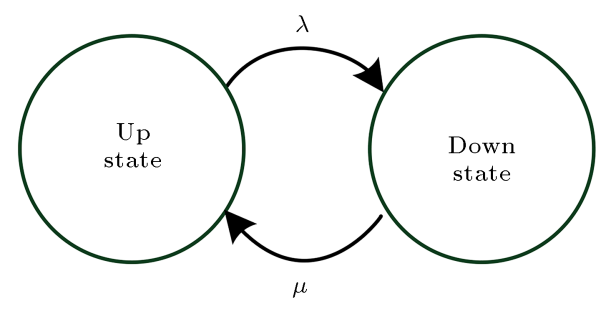

Figure 6. Two-state Marco model for each component.

The temperature of water on the surface of theocean varies from 20 to $30^{\circ} \mathrm{C}$ which affects the failure rate of components in contact with this water. Based on the Arrhenius theorem, the failure rate of these components at different temperatures is calculated as:

$$
\lambda(T)=\lambda_{0} e^{\left(-\frac{E_{a}}{k T}\right)} .
$$

In Eq. (14), $\lambda(T), \lambda_{0}, E_{a}, k$, and $T$ are the failure rate associated to temperature $T$ (in Kelvin degree), failure rate in the base temperature, activation energy, Boltzmann constant, and temperature, respectively [37]. For the components in contact with the water on the surface of the ocean, based on the temperature of each hour in the year, the average failure rate is calculated as:

$$
\lambda=\frac{\sum_{k=1}^{8760} \lambda\left(T_{h_{k}}\right)}{8760} .
$$

The equivalent failure and repair rate of the OTEC system can be determined easily based on the series components through Eq. (16) [36]:

$$
\lambda_{e q}=\sum_{i=1}^{14} \lambda_{i}, r_{e q}=\frac{\sum_{i=1}^{14} \lambda_{i} r_{i}}{\lambda_{e q}}, \mu_{e q}=\frac{1}{r_{e q}} .
$$

In Eq. (16), $\lambda_{e q}, \mu_{e q}$, and $r_{e q}$ are equivalent failure rate, equivalent repair rate, and equivalent repair time, respectively. The generated power of an OTEC system is dependent on the temperature of ocean surface water and because of the variation in these temperatures as can be seen in Figure 3, the generated powers are not fixed and vary with time, as can be seen in Figure 4. Based on this figure, the power generated by a $30 \mathrm{MW}$ closed-cycle OTEC power plant utilizing ammonia as working fluid constructed in Hawaii with temperature data obtained in the year 2016 can be utilized for assessing the reliability of the power system.

According to Figure 5, the generated power of a plant has numerous states that are not suitable for analytical reliability evaluation of a power system. Thus, the states of the power must be reduced using an appropriate clustering technique. Clustering methods are classified into two categories including hierarchical and partitioning clustering methods. 
The partitioning clustering method is categorized into the K-means clustering, FCM clustering, Gaussian expectation-maximization, K-harmonic means, and hybrid 2 algorithms. Among these clustering techniques, FCM clustering method allocates each data set to each cluster with some degrees of membership (i.e., fuzzy clustering) which is more appropriate in real applications where there are some overlaps between the clusters in the data set. The performance of the FCM clustering method is better than that of other clustering techniques and the effect of data uncertainty on this method is less significant [38]. Thus, due to the uncertainty of ocean surface temperature, this technique can be used to reduce the number of states in the reliability model of OTEC power plant. However, as in the case of K-means, the user is required to determine the number of clusters in the data set. Upon applying this robust approach, for a preset number of clusters, the center of clusters can be determined. This method categorizes the object data set $X=$ $\left[x_{1}, x_{2}, \ldots, x_{n}\right]$ into $\mathrm{m}$ fuzzy clusters for minimizing the following objective function [39]:

$$
J_{m}(U, v)=\sum_{i=1}^{m} \sum_{k=1}^{n} U_{i k}^{f}\left|x_{k}-v_{k}\right|
$$

where $f, v_{k}$, and $U_{i k}$ are fuzzy parameter, center of the $i$ th cluster, and fuzzy degree between $x_{k}$ and $i$ th cluster. In the FCM clustering approach, the user is required to specify the number of clusters in the data set. To determine the optimal number of clusters, various indices including the least Square Error (SE), Partition Coefficient (PC), Partition Entropy (PE), Fukuyama and Sugeno (FS), Xie-Beni (XB), Dunns Index (DI), Partition Coefficient and Exponential Separation (PCAES) [40,41], and techniques including using Information Theoretic Criterion have been considered [42]. Due to the suitability and good performance of XB index for obtaining the optimal number of reduced states which resulted in the frequent applications of this index in the literature review, this study employs the XB index to determine the optimal number of clusters in the reliability model of OTEC system, which is obtained when XB is at minimum. Thus, for determining the appropriate number of clusters, XB index is calculated as [43]:

$$
X B=\frac{J_{m}(U, v)}{n \times \min _{i \neq j}\left(\left|v_{i}-v_{j}\right|^{2}\right)} .
$$

The optimal number of clusters is determined when $\mathrm{XB}$ index is in the minimum value. By utilizing the generated power associated with the historical data as the input data of FCM clustering method, the number and probability of suitable clusters, which represent the appropriate states associated to the OTEC power

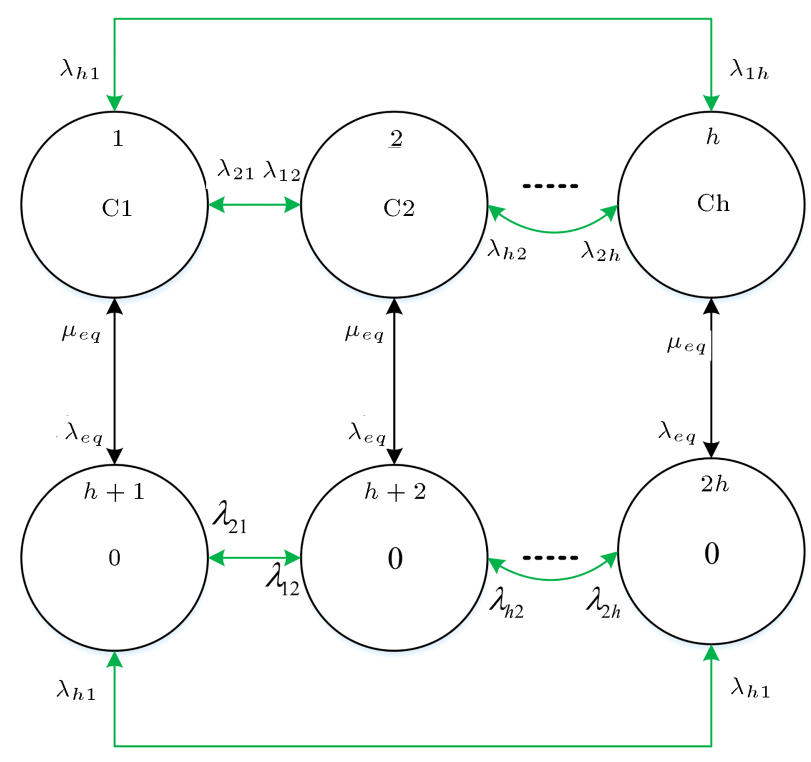

Figure 7. Complete reliability model of the closed-cycle ocean thermal energy conversion power plants.

plant, can be determined. If the clustering algorithm results in $h$ clusters, the complete reliability model of the closed-cycle OTEC power plant would be obtained, as is seen in Figure 7 . The states with zero capacity can be merged and a model with $(h+1)$ states be obtained.

\subsection{The CVaR concept in the OTEC systems}

The generated power of OTEC systems is dependent on the temperature of ocean surface and due to the variation in the ocean surface temperature, the output power of OTEC systems has stochastic behavior. The uncertainty of OTEC units puts the system at risk due to this probabilistic behavior. Thus, in this stage, a risk-based adequacy study of the power system integrated with the OTEC units is proposed. For a random variable such as ocean surface temperature $(T)$, in a given time horizon like a year, for $0<\alpha<1$, the $\alpha$-value at risk $\left(\operatorname{VaR}_{\alpha}(T)\right)$ can be calculated using Eq. (19). $V a R_{\alpha}(T)$ is the minimum ocean temperature and the probability of occurrence of the temperature below it is equal to $\alpha$ :

$$
\operatorname{VaR}_{\alpha}(T)=\min \{c \mid P(T \leq c) \geq \alpha\} .
$$

For the random variable ocean temperature, the $\alpha$-conditional value at risk $\left(C \operatorname{VaR}_{\alpha}(T)\right)$ can be calculated using Eq. (20). $C V a R_{\alpha}(T)$ is the expected value of the ocean temperatures which is more than $\operatorname{VaR}_{\alpha}(T)$.

$$
C \operatorname{VaR}_{\alpha}(T)=\frac{1}{1-\alpha} \sum_{T=V a R_{\alpha}(T)}^{T_{\max }}(T \times P(T)),
$$

where $P(T)$ is the probability of occurrence temperature $T$ and $T_{\max }$ is the maximum ocean temperature 


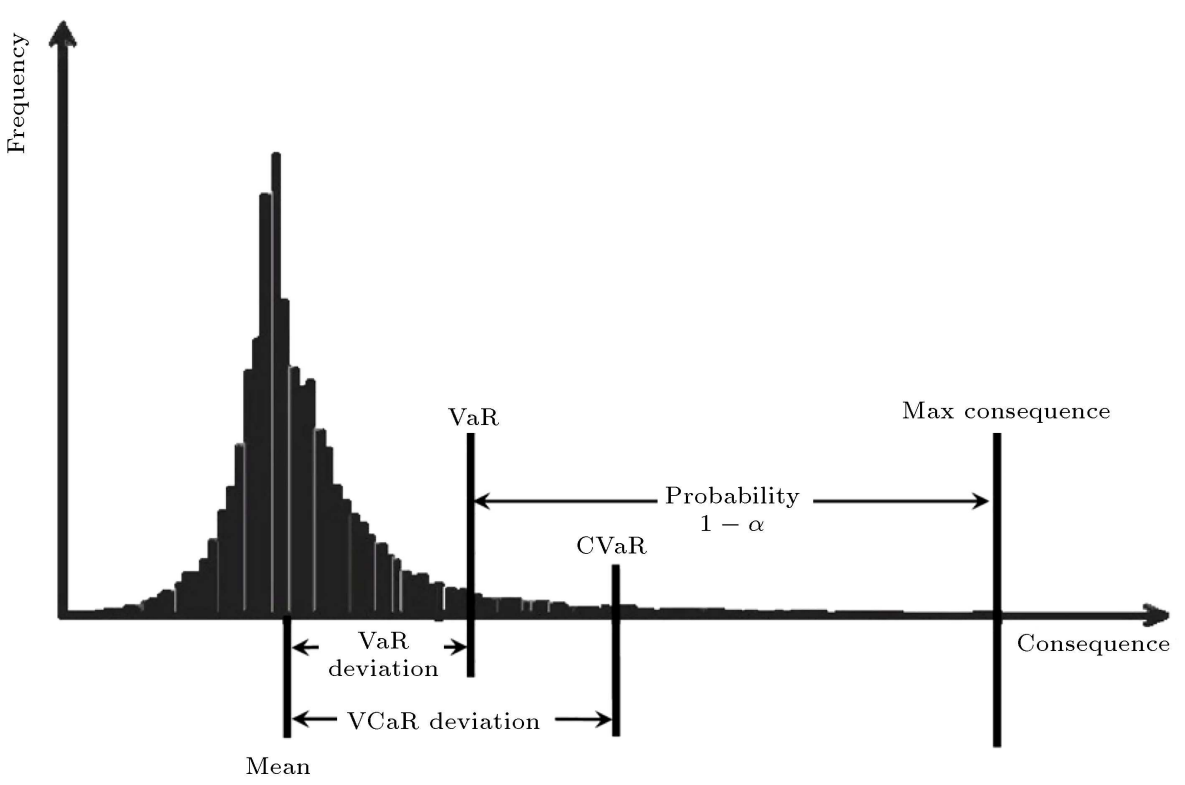

Figure 8. The concept of Value at Risk (VaR) and Conditional Value at Risk (CVaR).

occurring during the time horizon. The concept of VaR and CVaR is presented in Figure 8.

In this paper, variation in the ocean temperature leads to variation in the generated power and consequently, variation in the reliability indices. To study the effect of variation in the ocean temperature on the adequacy of the power system containing OTEC units, the reliability indices including Loss of Load Expectation (LOLE) and Expected Energy Not Supplied (EENS) considering different CVaR values associated to different values of $\alpha$ are determined. For this purpose, the generated power associated to different CVaR values is calculated and used for determining LOLE and EENS values.

\subsection{The technique to evaluate the adequacy of the power system containing OTEC system}

For investigating the adequacy of a generation power system containing OTEC power plants with a large capacity which can be integrated to the bulk power system, all generation units are considered to be connected to a common bus and the total load is connected to it, too. A Capacity Outage Probability Table (COPT), including different capacities and associated probabilities of the power plants, is constructed for conventional generation units including two states (up and down). Then, the multi-state reliability model of the OTEC power plants is added to this table and the total COPT of the system is constructed. Upon convolving the load model with the generation model, the adequacy indices including LOLE, EENS, Peak Load-Carrying Capability (PLCC), and Increase in Peak Load-Carrying Capability (IPLCC) are obtained simply. The LOLE is the hours in a year when part or the entire electric load is curtailed; the EENS is the value of energy in a year that the system cannot supply; the PLCC is the value of the peak load that the system can supply provided that the reliability criterion is satisfied; and IPLCC is the amount of peak load that can be added provided that the reliability criterion is satisfied when a new generation unit is added to the system. If the peak load is modeled through load duration curve with a straight line, the LOLE and EENS can be calculated using Eqs. (21) and (22) based on Figure 9:

$$
\begin{aligned}
& L O L E=\sum_{i=1}^{n} t_{i} \times P_{i} \text { hours/year, } \\
& E E N S=\sum_{i=1}^{n} E N S_{i} \times P_{i} .
\end{aligned}
$$

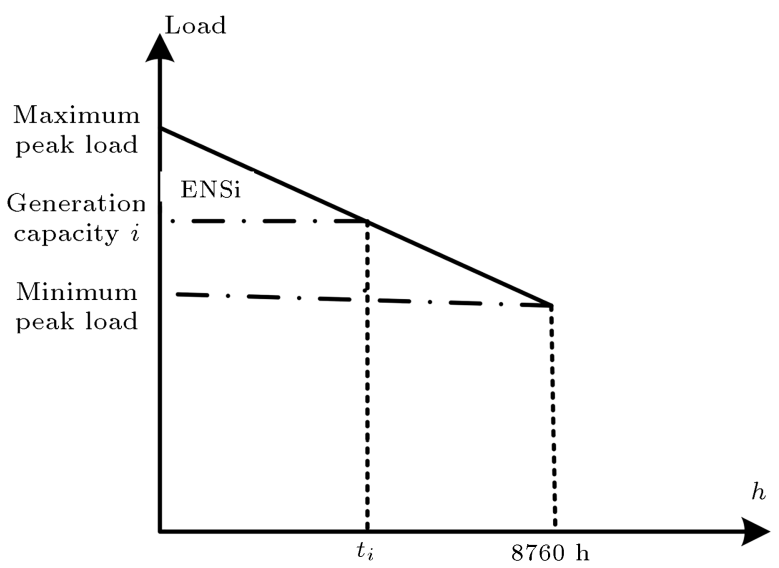

Figure 9. The method to calculate the loss of load expectation and Expected Energy Not Supplied (EENS). 


\subsection{The effect of transmission system on the adequacy studies}

In this part, the effect of transmission network on the reliability of the power system containing OTEC units is investigated. In this paper, to study the composite (generation and transmission) system reliability, contingency analysis approach is proposed. Each conventional generation unit and transmission line can be presented by two states including up and down states. However, due to the uncertainty of OTEC systems arising from variation in the generated power, each OTEC system can be presented by the multi-state model. Thus, a composite power system including $n$ generation units and $m$ transmission lines will have $2^{n+m}$ contingencies. The number of contingencies in the large-scale composite power system is very large which is not suitable for the adequacy of the composite power system. Therefore, through state selection, it is neglected from the contingencies with low probabilities and the number of contingencies is reduced. If an OTEC system with $h$ states is added to the composite system, the number of contingencies will be $h \times 2^{m+n}$. After reducing the contingencies using state selection, each selected contingency is evaluated. In this paper, to evaluate the contingencies, DC load flow considering the capacity of transmission lines is performed. If contingency results in load curtailment using the load shedding program to minimize the cost of interrupted loads, optimum load curtailment is determined. The objective function of the load shedding program is considered to be:

$$
\text { objective function }=\sum_{i=1}^{n} C_{i} V O L L_{i},
$$

where $C_{i}$ and $V O L L_{i}$ are the curtailed load and the value of lost load in $(\$ / M W h)$ associated to the load point $i$, respectively. In this paper, the linear programming approach based on the interior point method is utilized to optimize the objective function. To optimize the cost function, the problem constraints (e.g., the power balance equation must be established; the generated power of generation units must be within the permissible range; the interrupted load must be less than the maximum load; and the transmitted power of the transmission lines must be less than nominal capacity) are required to be satisfied. Based on the contingency analysis, adequacy study of the composite power system containing OTEC systems is performed and reliability indices such as the probability of lost load $\left(Q_{S}\right)$, LOLE, and EENS associated to each load point can be determined using Eqs. (24), (25), and (26), respectively, where $P_{i}$ is probability of state $i, B_{i}$ a binary number with two values of 0 and 1 in which 1 represents the state results in the load curtailment of the understudied bus, $n$ number of all states, and $L_{i}$ value of lost load of understudied

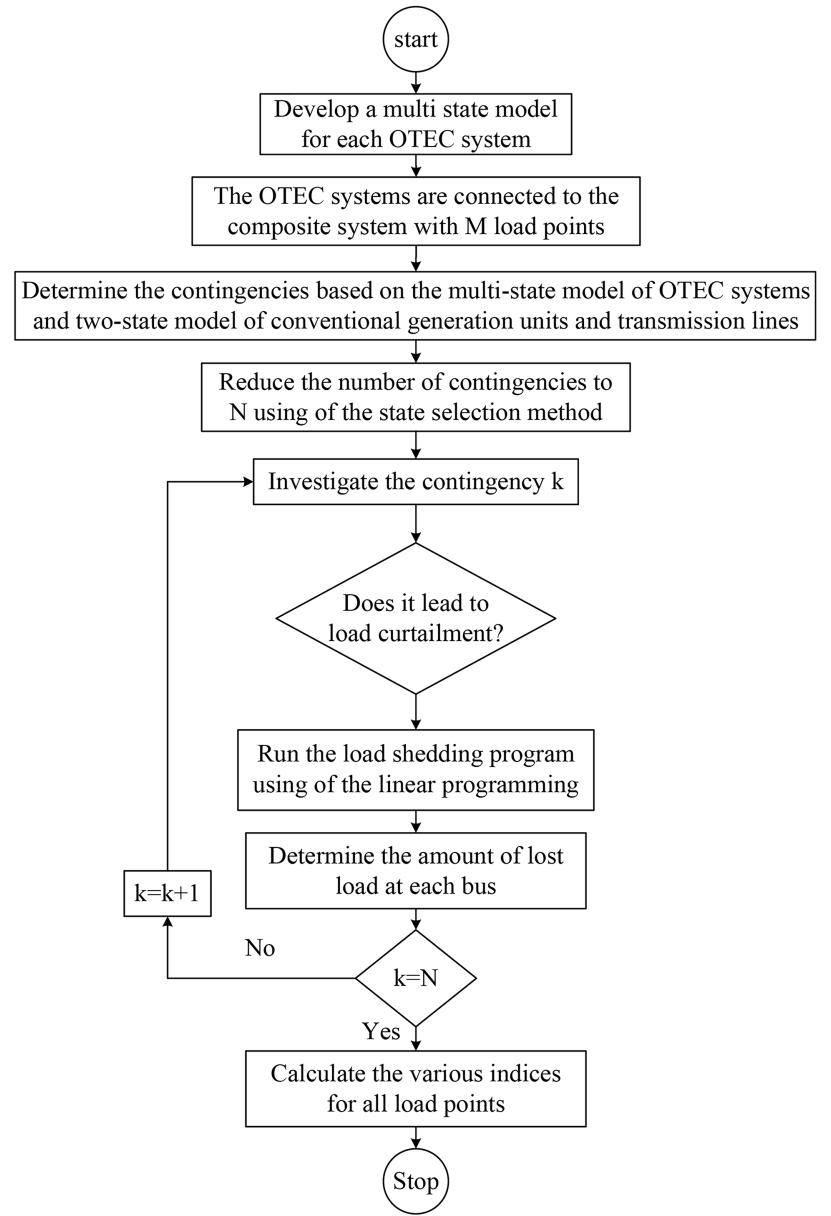

Figure 10. The flowchart associated to the adequacy assessment of composite power system.

load point associated to the state $i$. The flowchart of the adequacy assessment of a composite power system containing large-scale OTEC systems is presented in Figure 10.

$$
\begin{aligned}
& Q_{s}=\sum_{i=1}^{n} P_{i} B_{i}, \\
& L O L E=\sum_{i=1}^{n} P_{i} B_{i} \times 8760, \\
& E E N S=\sum_{i=1}^{n} L_{i} P_{i} \times 8760 .
\end{aligned}
$$

\section{Numerical results}

In this section, the proposed multi-state reliability model of closed-cycle OTEC power plants is developed for use in adequacy studies of RBTS and IEEE-RTS systems containing OTEC power plants. The reliability indices based on the CVaR concept are also calculated to study the effect of ocean temperature uncertainty on the reliability performance of the power system. 


\subsection{Reliability modeling of the understudied OTEC system}

The generated power by a $30 \mathrm{MW}$ closed-cycle OTEC power plant is presented in Figure 4. The histogram of the generated power is obtained and presented in Figure 11. Following the application of FCM clustering method to the generated power data and calculation of $\mathrm{XB}$ index seen in Figure 12, it was found that 3 clusters could model the generated power of the OTEC power plant under study. Figure 13 represents the fuzzy num-

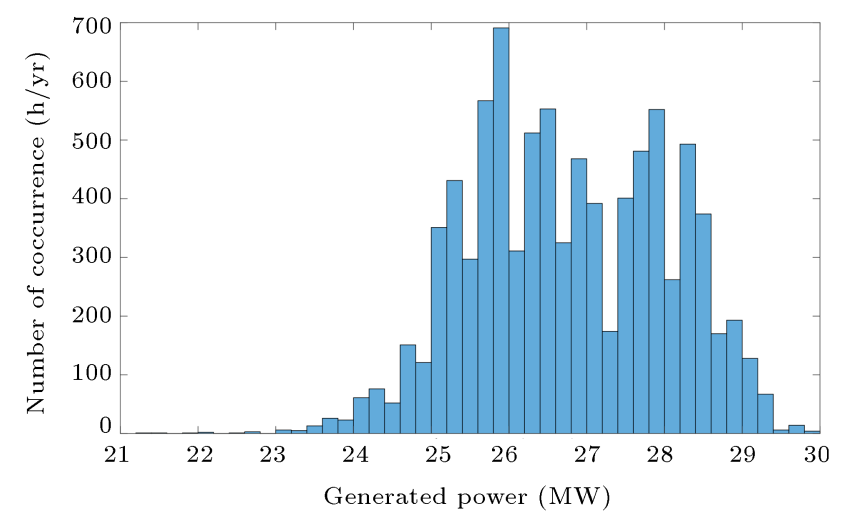

Figure 11. Histogram of generated power.

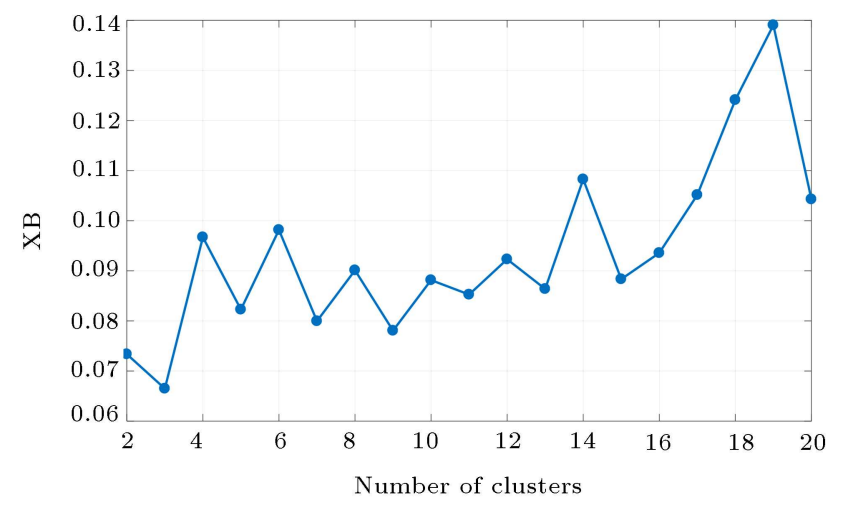

Figure 12. The Xie-Beni (XB) index associated to the generated power data.

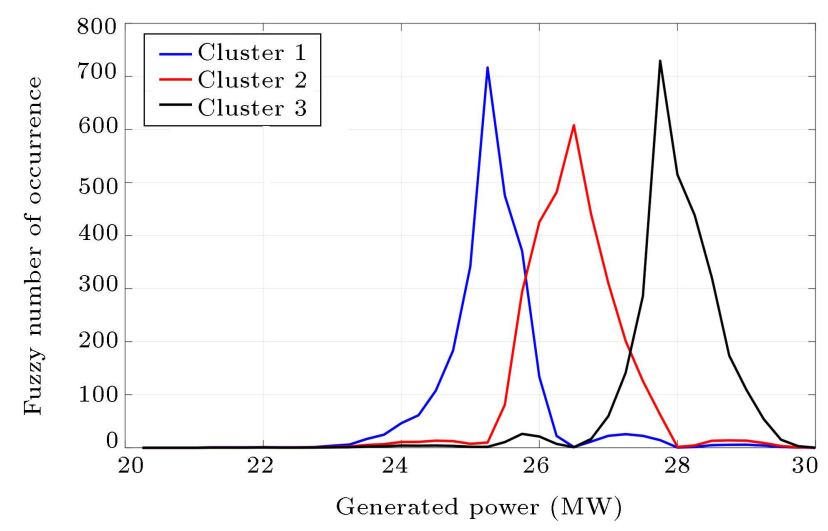

Figure 13. Fuzzy number associated to the generated power associated to the clusters.
Table 2. Three-state model of the ocean thermal energy conversion unit considering the uncertainty of variation in the temperature of the ocean surface.

\begin{tabular}{cccc}
\hline Capacity (MW) & 25.3 & 26.6 & 28.2 \\
Probability & 0.3619 & 0.3009 & 0.3372 \\
\hline
\end{tabular}

ber of different generated power data sets associated to every cluster. As can be seen in this figure, all data sets are concentrated around the clusters and the FCM clustering method can successfully model the entire generated power with three clusters. Table 2 shows the three-state reliability model of the OTEC power plant arising from the uncertainty of variation in the temperature of the ocean surface.

The failure rate and repair time of different components can be collected from manufacturers or operators during the operation of the power plant. Table 3 presents these reliability datasets [1-7]. The equivalent failure rate and repair time are calculated using Eqs. (14), (15), and (16). The availability and unavailability of the understudied power plant are calculated based on Eq. (13) as 0.86 and 0.14, respectively. The six-state complete reliability model of the OTEC power plant with a capacity of $30 \mathrm{MW}$ is obtained by combining the 3 -state model given in Table 2 with the two-state model derived from the failure of components (including full capacity with probability 0.86 and zero capacity with probability 0.14). By merging zerocapacity states, a four-state model presented in Table 4 is obtained for reliability modeling of the OTEC power plant under study. Based on the CVaR approach, VaR and CVaR associated to different alpha values are calculated and presented in Figure 14 to model the uncertainty of ocean temperature variation. It is deduced from this figure that the value of CVaR is higher than that of VaR.

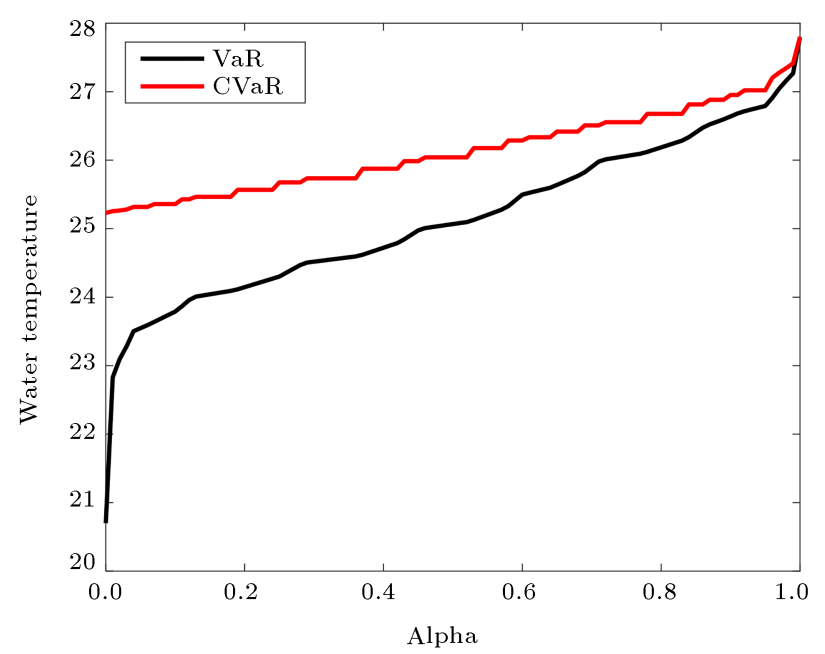

Figure 14. Value at Risk (VaR) and Conditional Value at Risk (CVaR) associated to the ocean temperature considering alpha. 
Table 3. The failure rate and repair time of ocean thermal energy conversion power plant components.

\begin{tabular}{ccc}
\hline Component & Failure rate (occ.yr) & Repair time (h) \\
\hline Main structure & 2 & 120 \\
Mooring system & 2 & 120 \\
Pipes & 2 & 120 \\
Turbine & 0.5 & 48 \\
Generator & 0.5 & 48 \\
Evaporator & 1 & 72 \\
Condenser & 1 & 72 \\
Working fluid pump & 1 & 48 \\
Warm water pump & 1 & 48 \\
Cold water pump & 1 & 48 \\
Electrical converter & 0.2 & 24 \\
Control system & 0.2 & 24 \\
Transformer & 0.5 & 72 \\
Cable & 1 & 72 \\
Total & 13.9 & 84.4 \\
\hline
\end{tabular}

Table 4. Four-state model of the ocean thermal energy conversion power plant.

\begin{tabular}{ccccc}
\hline Capacity (MW) & 25.3 & 26.6 & 28.2 & 0 \\
Probability & 0.3112 & 0.2588 & 0.2900 & 0.14 \\
\hline
\end{tabular}

\subsection{Adequacy assessment of RBTS}

In this part, adequacy assessment of RBTS containing the OTEC power plant is performed. The generation and reliability parameters of RBTS, with $240 \mathrm{MW}$ capacity including generation capacity, failure rate, and repair time of the units were given in [44]. The load is modeled based on the load duration curve and is considered to be a straight line from the maximum to minimum hourly peak load. Three cases including original RBTS and RBTS containing a new $30 \mathrm{MW}$ conventional unit with availability 0.95 as well as RBTS containing the OTEC unit are considered to be Cases 1 to 3 , respectively, to evaluate the effect of OTEC units on the adequacy indices of power systems. The LOLE and EENS of three cases considering the peak load are calculated and presented in Figures 15 and 16 , respectively. As can be seen in the figures, increasing the peak load results in increase in the values of LOLE and EENS indices; thus, the reliability of power system gets worse. Although the addition of a new generation unit enhances the reliability indices, conventional units may still improve the reliability indices to a greater degree, compared to OTEC units. The reliability index is arisen from the uncertainty nature of OTEC power plants that makes the generation capacity of the OTEC units due to the variation in the ocean temperature would be less than full capacity in the most times of the year. To make a clear comparison between the

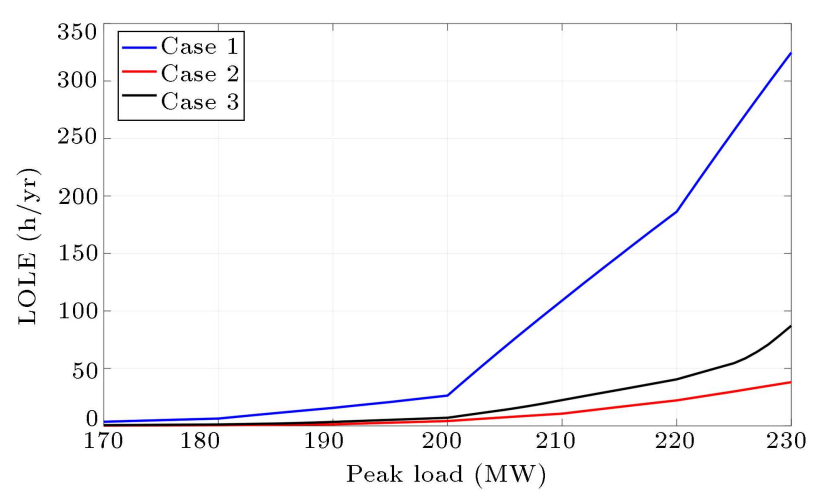

Figure 15. The loss of load expectation considering peak load.

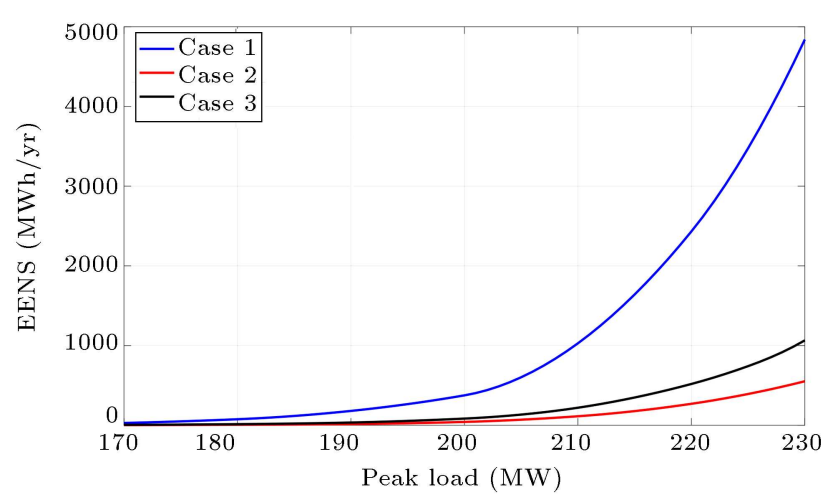

Figure 16. The expected energy not supplied considering peak load.

OTEC units and conventional ones of equal capacity in terms of reliability, PLCC and IPLCC are calculated based on the EENS criterion and are presented in Tables 5 and 6 . To calculate PLCC, the peak load increases as along as the EENS of the system is less 
Table 5. The peak load carrying capability for three cases.

\begin{tabular}{cccc}
\hline Cases & EENS $<\mathbf{1 0 0} \mathbf{M W h} / \mathbf{y r}$ & $\mathbf{E E N S}<\mathbf{2 0 0} \mathbf{M W h} / \mathbf{y r}$ & $\mathbf{E E N S}<\mathbf{3 0 0} \mathbf{M W h} / \mathbf{y r}$ \\
\hline Case 1 & $183 \mathrm{MW}$ & $191 \mathrm{MW}$ & $196 \mathrm{MW}$ \\
Case 2 & $208 \mathrm{MW}$ & $216 \mathrm{MW}$ & $221 \mathrm{MW}$ \\
Case 3 & $202 \mathrm{MW}$ & $209 \mathrm{MW}$ & $213 \mathrm{MW}$ \\
\hline
\end{tabular}

Table 6. Increase in peak load-carrying capability for Cases 2 and 3.

\begin{tabular}{cccc}
\hline Cases & EENS $<\mathbf{1 0 0} \mathbf{M W h} / \mathbf{y r}$ & EENS $<\mathbf{2 0 0} \mathbf{M W h} / \mathbf{y r}$ & $\mathbf{E E N S}<\mathbf{3 0 0} \mathbf{M W h} / \mathbf{y r}$ \\
\hline Case II & $25 \mathrm{MW}$ & $25 \mathrm{MW}$ & $25 \mathrm{MW}$ \\
Case III & $19 \mathrm{MW}$ & $18 \mathrm{MW}$ & $17 \mathrm{MW}$ \\
\hline
\end{tabular}

than the permissible value. According to these tables, the addition of a new generation unit results in increase in the capability of the power system to supply loads. However, due to the uncertainty of the OTEC units, increase in the capability of the power system with the addition of conventional units is greater than the cases of the addition of the OTEC power plants with the same capacity.

To study the effect of the uncertainty of ocean temperature variation on the adequacy indices of the power system, in this stage, the reliability indices including LOLE and EENS considering different values of $\mathrm{CVaR}$ are calculated and presented in Figures 17 and 18, respectively. According to this figure, due to the ocean temperature variation, the effect of OTEC system on the reliability indices, being dependent on the temperature value, is different. When the ocean temperature is higher and is associated to the higher alpha, the generated power of the OTEC system is higher and the LOLE and EENS of the power system are lower in value.

\subsection{Adequacy assessment of IEEE-RTS}

In this part, the IEEE-RTS with a higher generation capacity than RBTS is considered as a test system to evaluate the impacts of the OTEC units on the adequacy of the power system. The generation capacity of and the data reliability for this system were given in [45]. The LOLE and EENS values considering different peak loads in three cases including original IEEE-RTS as Case 1, IEEE-RTS with a 30-MW conventional unit with 0.95 availability as Case 2, and IEEE-RTS containing a 30-MW OTEC unit as Case 3 are calculated and presented in Figures 19 and 20, respectively. Also, the PLCC and IPLCC of these cases based on the EENS criterion are calculated, as given in Tables 7 and 8 . According to the figure and tables, the addition of a new generation unit results in improvement of the reliability indices. However, due to the uncertainty of the OTEC power plants derived from the ocean temperature variation, the OTEC power plant cannot enhance the reliability indices as much as the conventional units do, with the same capacity.

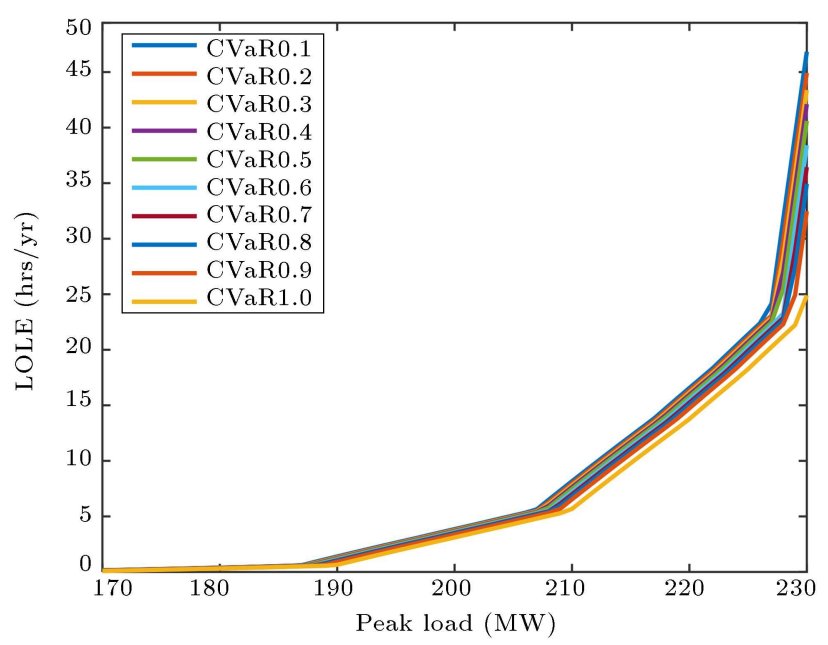

Figure 17. The loss of load expectation considering CVaR.

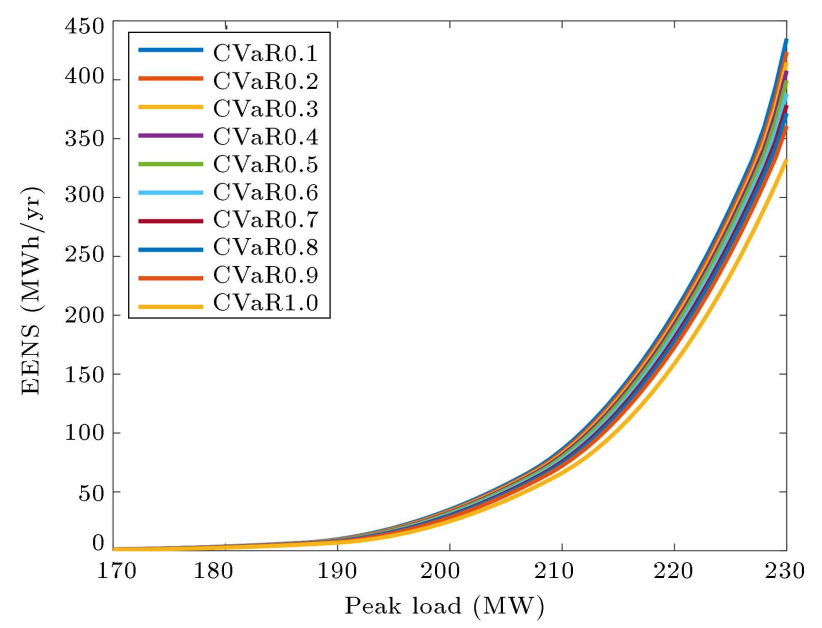

Figure 18. The expected energy not supplied considering CVaR.

\subsection{Adequacy assessment of the composite power system}

In this part, based on the proposed technique, the adequacy of the RBTS system as a composite power system is investigated to evaluate the effect of OTEC systems on the reliability of composite power systems. The transmission network of RBTS, which was 
Table 7. The peak load-carrying capability for three cases.

\begin{tabular}{cccc}
\hline Case & EENS $<\mathbf{1 5} \mathbf{G W h} / \mathbf{y r}$ & EENS $<\mathbf{2 0} \mathbf{G W h} / \mathbf{y r}$ & $\mathbf{E E N S}<\mathbf{2 5} \mathbf{G W h} / \mathbf{y r}$ \\
\hline Case 1 & $2830 \mathrm{MW}$ & $2876 \mathrm{MW}$ & $2912 \mathrm{MW}$ \\
Case 2 & $2860 \mathrm{MW}$ & $2906 \mathrm{MW}$ & $2942 \mathrm{MW}$ \\
Case 3 & $2854 \mathrm{MW}$ & $2899 \mathrm{MW}$ & $2936 \mathrm{MW}$ \\
\hline
\end{tabular}

Table 8. The increase in peak load-carrying capability for Cases 2 and 3.

\begin{tabular}{cccc}
\hline Cases & EENS $<\mathbf{1 5} \mathbf{G W h} / \mathbf{y r}$ & EENS $<\mathbf{2 0} \mathbf{G W h} / \mathbf{y r}$ & $\mathbf{E E N S}<\mathbf{2 5} \mathbf{G W h} / \mathbf{y r}$ \\
\hline Case 2 & $30 \mathrm{MW}$ & $30 \mathrm{MW}$ & $30 \mathrm{MW}$ \\
Case 3 & $24 \mathrm{MW}$ & $23 \mathrm{MW}$ & $24 \mathrm{MW}$ \\
\hline
\end{tabular}

Table 9. Reliability indices of composite RBTS.

\begin{tabular}{cccc}
\hline $\begin{array}{c}\text { Load } \\
\text { points }\end{array}$ & $\begin{array}{c}\text { Loss of } \\
\text { load probability }\end{array}$ & $\begin{array}{c}\text { Loss of } \\
\text { load expectation } \\
\text { (hrs/yr) }\end{array}$ & $\begin{array}{c}\text { Expected energy } \\
\text { not supplied } \\
\text { (MWh/yr) }\end{array}$ \\
\hline 2 & 0 & 0 & 0 \\
3 & 0.0086 & 75.34 & 6403.9 \\
4 & 0 & 0 & 0 \\
5 & $1.2733 \mathrm{e}-06$ & 0.01115 & 0.223 \\
6 & 0.00114012 & 9.9874512 & 199.749024 \\
\hline
\end{tabular}

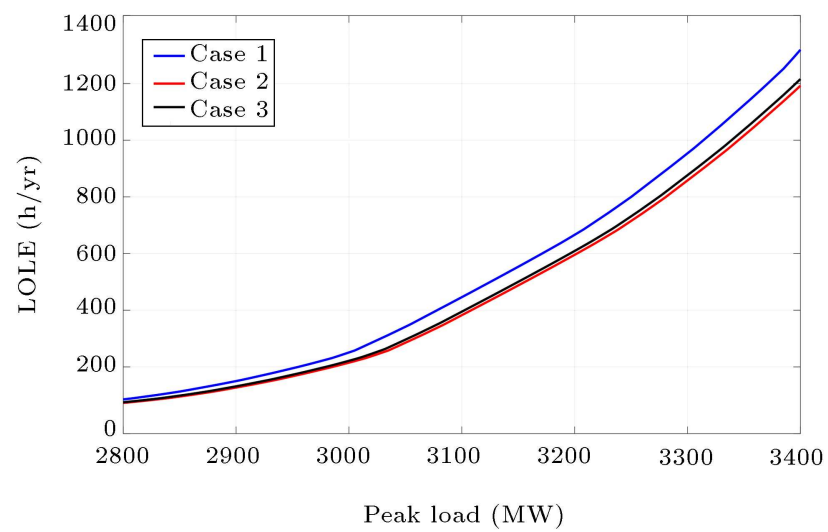

Figure 19. The loss of load expectation considering peak load.

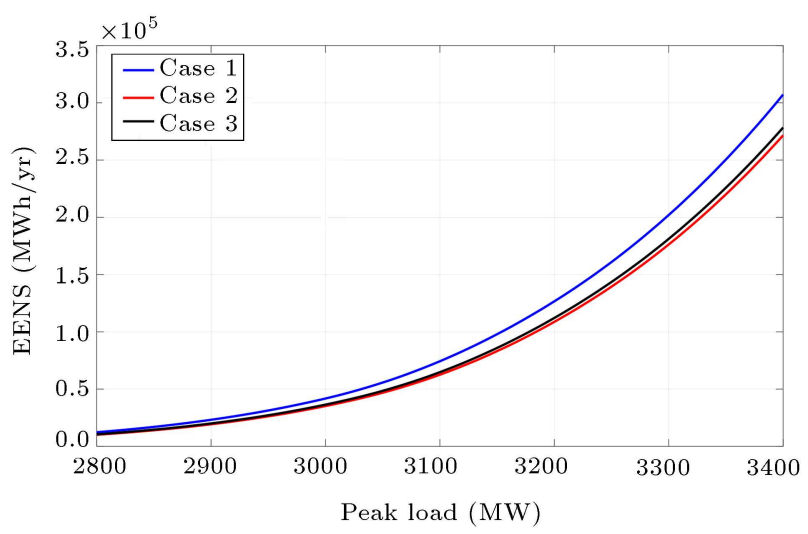

Figure 20. The expected energy not supplied considering peak load. given in [44], is considered in reliability computations. To evaluate the composite power system containing OTEC system, the contingencies associated to the simultaneous failures of up to 4 generation units, up to 3 transmission lines, and up to 3 generation units and transmission lines are considered. Based on the proposed technique, the reliability indices of the composite RBTS are calculated and presented in Table 9. According to the table, the reliability indices of load point 3 are very poor and thus, the OTEC unit is added to the RBTS system at this bus. The reliability indices of the RBTS integrated into the OTEC system are calculated and presented in Table 10. Based on the table, the addition of the OTEC system to the load point 3 results in the improvement in the reliability indices of this bus.

\section{Conclusion}

For the first time, this study managed to investigate the integration of Ocean Thermal Energy Conversion (OTEC) power plants into the power system in terms of reliability. To this end, a multi-state reliability model was developed considering both the failure of composed components and variation in the generated power arising from the variation in the ocean temperature for these units. For state reduction of the model, Fuzzy C-Means (FCM) clustering technique was applied and to determine the proper number of clusters, the Xie and Beni (XB) index was implemented. The proposed 
Table 10. Reliability indices of composite RBTS integrated to the ocean thermal energy conversion unit at point 3.

\begin{tabular}{cccc}
\hline $\begin{array}{c}\text { Load } \\
\text { points }\end{array}$ & $\begin{array}{c}\text { Loss of } \\
\text { load probability }\end{array}$ & $\begin{array}{c}\text { Loss of } \\
\text { load expectation } \\
\text { (hrs/yr) }\end{array}$ & $\begin{array}{c}\text { Expected energy } \\
\text { not supplied } \\
\text { (MWh/yr) }\end{array}$ \\
\hline 2 & 0 & 0 & 0 \\
3 & 0.0003 & 2.628 & 223.38 \\
4 & 0 & 0 & 0 \\
5 & $1.2733 \mathrm{e}-06$ & 0.01115 & 0.223 \\
6 & 0.00114009 & 9.9871884 & 199.743768 \\
\hline
\end{tabular}

multi-state model was applied to the adequacy of the power systems in the presence of the OTEC power plants. It was deduced from the numerical results associated to the adequacy of Roy Billinton Test System (RBTS) and IEEE Reliability Test System (IEEE-RTS) in the presence of the OTEC power plant that these plants could improve the reliability indices of the power system; however, due to the uncertainty of these plants arising from the generated power variation, this improvement was less than that achieved by the conventional generation units with the same capacity. The numerical results indicated that the CVaR modeled the uncertainty of ocean surface temperature and it could be used in the renewable-based power systems to study the effect of variation in the generated power of renewable resources on the adequacy indices of the power system. According to the numerical results, the proposed technique effectively calculated the reliability indices. This analytical technique had a lower computational volume than numerical methods such as Monte Carlo and did not have the problems of the simulation-based approach including low convergence speed, high computation time, and large memory volume required.

\section{Nomenclature}

$P_{G} \quad$ Produced power of the generator

$P_{W F P} \quad$ Power needed for pumping working fluid

$P_{W W P} \quad$ Power needed for pumping warm waters

$P_{C W P} \quad$ Power needed for pumping cold waters

$\dot{m}_{W F} \quad$ Mass flow rate of the working fluid in $\mathrm{kg} / \mathrm{s}$

$\eta_{G} \quad$ Generator efficiency

$\eta_{T} \quad$ Turbine efficiency

$h_{1} \quad$ Enthalpy of evaporator outlet (turbine inlet)

$h_{2} \quad$ Enthalpy of condenser inlet (turbine outlet)

\begin{tabular}{|c|c|}
\hline$\dot{m}_{W F}$ & Mass flow rate of the working fluid \\
\hline$\dot{m}_{W W}$ & $\begin{array}{l}\text { Mass flow rate of warm water (ocean } \\
\text { surface water) }\end{array}$ \\
\hline$\dot{m}_{c w}$ & $\begin{array}{l}\text { Cold water mass flow rate (water at } \\
800-1000 \mathrm{~m} \text { deep) }\end{array}$ \\
\hline$g$ & Acceleration of gravity in $\mathrm{m} / \mathrm{s}^{2}$ \\
\hline$h_{W F}$ & $\begin{array}{l}\text { Total pressure difference associated to } \\
\text { the working fluid }\end{array}$ \\
\hline$h_{W W}$ & $\begin{array}{l}\text { Total pressure difference associated to } \\
\text { the warm seawater }\end{array}$ \\
\hline$h_{C W}$ & $\begin{array}{l}\text { Total pressure difference associated to } \\
\text { the cold seawater }\end{array}$ \\
\hline$\eta_{W F P}$ & Efficiency of working fluid pumping \\
\hline$\eta_{W W P}$ & Efficiency of warm water pumping \\
\hline$\eta_{C W P}$ & Efficiency of cold water pumping \\
\hline$Q_{E}$ & Heat transfer rate of the evaporator \\
\hline$Q_{C}$ & Heat transfer rate of the condenser \\
\hline$h_{3}$ & $\begin{array}{l}\text { Enthalpy of the input of the working } \\
\text { fluid pumping }\end{array}$ \\
\hline$h_{4}$ & $\begin{array}{l}\text { Enthalpy of the output of the working } \\
\text { fluid pumping }\end{array}$ \\
\hline$s$ & Entropy \\
\hline$x$ & Quality \\
\hline$\lambda$ & Failure rate of the components \\
\hline$\mu$ & Repair rate of the components \\
\hline$P_{u p}$ & Probabilities associated to the up-state \\
\hline$P_{\text {down }}$ & $\begin{array}{l}\text { Probabilities associated to the } \\
\text { down-state }\end{array}$ \\
\hline$\lambda_{e q}$ & Equivalent failure rate \\
\hline$\mu_{e q}$ & Equivalent repair rate \\
\hline$r_{e q}$ & Equivalent repair time \\
\hline$C$ & Capacity \\
\hline$f$ & Fuzzy parameter \\
\hline$v_{k}$ & Center of the $i$ th state \\
\hline$U_{i k}$ & $\begin{array}{l}\text { Fuzzy degree between data } x_{k} \text { and the } \\
i \text { th state }\end{array}$ \\
\hline$P_{f}$ & Probability of failure of component \\
\hline
\end{tabular}




\section{Abbreviations}

$\begin{array}{ll}\text { OTEC } & \text { Ocean Thermal Energy Conversion } \\ \text { EENS } & \text { Expected Energy Not Supplied } \\ \text { FCM } & \text { Fuzzy C-Means } \\ \text { COPT } & \text { Capacity Outage Probability Table } \\ \text { MCS } & \text { Monte Carlo Simulation } \\ \text { VaR } & \text { Value at Risk } \\ \text { CVaR } & \text { Conditional Value at Risk } \\ \text { LOLE } & \text { Loss Of Load Expectation } \\ \text { LOLP } & \text { Loss Of Load Probability } \\ \text { XB } & \text { Xie-Beni } \\ \text { PLCC } & \text { Peak Load-Carrying Capability } \\ \text { IPLCC } & \text { Increase in Peak Load-Carrying } \\ & \text { Capability } \\ \text { RBTS } & \text { Roy Billinton Test System } \\ \text { IEEE-RTS } & \text { IEEE Reliability Test System }\end{array}$

\section{References}

1. Engels, W. and Zabihian, F. "Principle and preliminary calculation of ocean thermal energy conversion", ASEE 2014 Zone I Conference, Bridgeport, USA (2014).

2. Bybee, K. "Ocean-thermal-energy conversion", Journal of Petroleum Technology, 61(7), pp. 65-66 (2009).

3. Balakumar, S. and Sathivel, C. "Study of ocean thermal energy conversion power plant", SSRG International Journal of Thermal Engineering (SSRGIJTE), 1(3), pp. 1-13 (2015).

4. Masutani, S.M. and Takahashi, P.K. "Ocean thermal energy conversion (OTEC)", Oceanography, 22(609), p. 625 (2001).

5. Lee, H.S., Jung, Y.K., Kim, H.J., et al. "Manufacturing and testing mock-up for commercialization of the ocean thermal energy conversion $(50 \mathrm{MW})$ power plant", IEEE Oceans, Yeosu, 1(1), pp. 1-5 (2012).

6. Najafi, A., Rezaee, S., and Torabi, F. "Sensitivity analysis of a closed cycle ocean thermal energy conversion power plant", IEEE Second Iranian Conference on Renewable Energy and Distributed Generation (ICREDG), Iran, pp. 1-6 (2012).

7. Najafi, A., Rezaee, S., and Torabi, F. "Multi-objective optimization of ocean thermal energy conversion power plant via genetic algorithm", IEEE Electrical Power and Energy Conference (EPEC), pp. 41-46 (2011).

8. Kim, H.J., Lee, H.S., Lee, S.W., et al. "Mitigation of environmental impact of power-plant discharge by use of ocean thermal energy conversion system", IEEE Oceans, Sydney, pp. 1-4 (2010).

9. Wang, S.K. and Hung, T.C. "Renewable energy from the sea-organic Rankine Cycle using ocean thermal energy conversion", IEEE International Conference on Energy and Sustainable Development: Issues and Strategies (ESD), pp. 1-8 (2010).

10. Zhang, S., Li, Y., Bai, Y., et al. "An assessment of ocean thermal energy conversion resources in the South China Sea", IEEE Oceans, Shanghai, pp. 1-6 (2016).

11. Wanjun, W., Fuyuan, W., Xiangyu, L., et al. "Ocean energy comprehensive utilization system of waterelectricity cogeneration", The Journal of Engineering, 13, pp. 1362-1366 (2017).

12. Von Jouanne, A. and Brekken, T.K. "Ocean and geothermal energy systems", Proceedings of the IEEE, 105(11), pp. 2147-2165 (2017).

13. Shahidehpour, M. and Fotuhi-Friuzabad, M. "Grid modernization for enhancing the resilience, reliability, economics, sustainability, and security of electricity grid in an uncertain environment", Scientia Iranica, Transaction D, Computer Science \& Engineering, Electrical, 23(6), pp. 2862-2873 (2016).

14. Shi, Z.S., Wang, R., Zhang, X.Y., et al. "Optimal design of grid-connected hybrid renewable energy systems using multi-objective evolutionary algorithm", Scientia Iranica, 24(6), pp. 3148-3156 (2017).

15. Ghaedi, A., Abbaspour, A., Fotuhi-Friuzabad, M., et al. "Incorporating large photovoltaic farms in power generation system adequacy assessment", Scientia Iranica, 21(3), pp. 924-934 (2014).

16. Haghi, A. and Rahimi, M. "Control and stability analysis of VSC-HVDC based transmission system connected to offshore wind farm", Scientia Iranica, 29(1), pp. 193-207 (2019).

17. Eslaminia, M., Mohammadian, M., and Hemmatpour, M.H. "An approach for increasing wind power penetration in deregulated power systems", Scientia Iranica, Transaction D, Computer Science \& Engineering, Electrical, 23(3), pp. 1282-1293 (2016).

18. Doostizadeh, M., Shakarami, M.R., and Bastami, H. "A decentralized energy trading framework for active distribution networks with multiple-microgrids under uncertainty", Scientia Iranica, 26, pp. 3606-3621 (2019).

19. Torkaman, H., Khosrogorji, S., and Ghari, H. "Optimal sizing of hybrid WT/PV/Diesel generator/battery system using MINLP method for a region in Kerman", Scientia Iranica, 27, pp. 3066-3074 (2019).

20. Bitzenis, Aristidis, Panagiotis Kontakos, and Charisios Kafteranis. "Renewable policies and challenges by 2020 in Greece: A questionnaire survey", Scientia Iranica, 25(1), pp. 359-369 (2018).

21. Hassanzadeh, M.N., Fotuhi-Firuzabad, M., Safdarian, 
A., et al. "Demand response as a complement for wind energy from system well-being Viewpoint", Scientia Iranica, 27(3), pp. 1373-1383 (2018).

22. Fan, M., Sun, K., Lane, D., et al. "A novel generation rescheduling algorithm to improve power system reliability with high renewable energy penetration", IEEE Transactions on Power Systems, 33(3), pp. 3349-3357 (2018).

23. Tómasson, E. and Söder, L. "Generation adequacy analysis of multi-area power systems with a high share of wind power", IEEE Transactions on Power Systems, 33(4), pp. 3854-3862 (2017).

24. Su, S., Hu, Y., He, L., et al. "An assessment procedure of distribution network reliability considering photovoltaic power integration", IEEE Access, 7, pp. 60171-60185 (2019).

25. Farzin, H., Fotuhi-Firuzabad, M., and Moeini-Aghtaie, M. "Reliability studies of modern distribution systems integrated with renewable generation and parking lots", IEEE Transactions on Sustainable Energy, 8(1), pp. 431-440 (2016).

26. Abunima, H., Teh, J., and Jabir, H.J. "A new solar radiation model for a power system reliability study", IEEE Access, 7, pp. 64758-64766 (2019).

27. Nguyen, N., Almasabi, S., and Mitra, J. "Impact of correlation between wind speed and turbine availability on wind farm reliability", IEEE Transactions on Industry Applications, 55(3), pp. 2392-2400 (2019).

28. Sulaeman, S., Benidris, M., Mitra, J., et al. "A wind farm reliability model considering both wind variability and turbine forced outages", IEEE Transactions on Sustainable Energy, 8(2), pp. 629-637 (2016).

29. Wu, Y.K., Su, P.E., Su, Y.S., et al. "Economics-and reliability-based design for an offshore wind farm", IEEE Transactions on Industry Applications, 53(6), pp. 5139-5149 (2017).

30. Gazijahani, F.S., Ravadanegh, S.N., and Salehi, J. "Stochastic multi-objective model for optimal energy exchange optimization of networked microgrids with presence of renewable generation under risk-based strategies", ISA Transactions, 73, pp. 100-111 (2018).

31. Bremermann, L., Rosa, M., Gálvis, P., et al. "Using VaR and CVaR techniques to calculate the long-term operational reserve", IEEE International Conference on Probabilistic Methods Applied to Power Systems (PMAPS), pp. 1-7 (2016).

32. Bukhsh, W.A., Papakonstantinou, A., and Pinson, P. "A robust optimisation approach using CVaR for unit commitment in a market with probabilistic offers", IEEE International Energy Conference (ENERGYCON), pp. 1-6 (2016).

33. Khodabakhsh, R. and Sirouspour, S. "Optimal control of energy storage in a microgrid by minimizing condi- tional value-at-risk", IEEE Transactions on Sustainable Energy, 7(3), pp. 1264-1273 (2016).

34. Li, K., Zhang, J., Che, J., et al. "Capacity configuration optimization for stand-alone microgrid considering the uncertainties of wind and solar resource", IEEE Power \& Energy Society Innovative Smart Grid Technologies Conference (ISGT), pp. 1-5 (2018).

35. Kenneth, W., Thermodynamics, 4th Ed., McGrawHill, New York (1983).

36. Billinton, R. and Allan, R.N., Reliability Evaluation of Power Systems, 2nd Ed., New York Plenum, NY, USA and London, U.K. (1994).

37. Badran, O., Sarhan, H., and Alomour, B. "Thermal performance analysis of induction motor", International Journal of Heat and Technology, 30(1), pp. 7588 (2012).

38. Omran, M.G., Engelbrecht, A.P., and Salman, A. "An overview of clustering methods", Intelligent Data Analysis, 11(6), pp. 583-605 (2007).

39. Cannon, R.L., Jitendra, V.D., and Bezdek, J.C. "Efficient implementation of the fuzzy c-means clustering algorithms", IEEE Trans. Pattern Analysis and Machine Intelligence, 8(2), pp. 248-255 (1986).

40. Chen, M. and Ludwig, S.A. "Particle swarm optimization based fuzzy clustering approach to identify optimal number of clusters", Journal of Artificial Intelligence and Soft Computing Research, 4(1), pp. 43-56 (2014).

41. Mahdizadeh, E., Saadinezhad, S., and Tavakoli, M.R. "Optimization of fuzzy clustering criteria by a hybrid PSO and fuzzy c-means clustering algorithm", Iranian Journal of Fuzzy Systems, 5(3), pp. 1-14 (2008).

42. Oubrahim, Z., Choqueuse, V., Amirat, Y., et al. "Classification of three-phase power disturbances based on model order selection in smart grid applications", 42nd IECON Annual Conference of the IEEE Industrial Electronics Society, pp. 5143-5148 (2016).

43. Liang, Z., Zhang, P., and Zhao, J. "Optimization of the number of clusters in fuzzy clustering", IEEE International Conference on Computer Design and Applications (ICCDA), 3, pp. 580-584 (2010).

44. Billinton, R., Kumar, S., Chowdhury, N., et al. "A reliability test system for educational purposes-basic data", IEEE Power Engineering Review, 9(8), pp. 6768 (1989).

45. Reliability Test System Task Force of the Application of Probability Methods subcommittee, "IEEE reliability test system", IEEE Trans. Power App. Syst., 98(6), pp. 2047-2054 (1979).

\section{Biographies}

Khodakhast Nasiriani was born on April 24, 1981 in Kazeroon, Iran. He received his BS and MS degrees in Electrical Engineering in 2002 and 2012 from Islamic Azad University. $\mathrm{He}$ is a PhD student 
in Power Electrical. He has been a staff member of NIOC (National Iranian Oil Company) from 2005 up to now. He is an Electrical Inspector Engineer. He has experience in teaching and his research interests include electrical safety and lightening protection system of oil tank, reliability, renewable resources, and high voltage engineering.

Amir Ghaedi was born in 1984 in Kheirabad, Shiraz and received $\mathrm{PhD}$ degree in 2013 in Electrical Engineering and Power Field from Sharif University of Technology. He is currently a faculty member and also, the Head of the Islamic Azad University, Dariun Branch, Iran. His main research interests are the power quality, power system reliability, smart grids, renewable resources, and high voltage engineering.

Mehdi Nafar was born on April 24, 1979 in Marvdasht, Iran. He received his BS, MS, and PhD degrees in Electrical Engineering in 2002, 2004, and 2011 from PWIT University, Amirkabir University of Technology (AUT), and Islamic Azad University, Science and Research Branch, Tehran, Iran, respectively, all graduated with First Class Honors. He is an Assistant Professor at the Electrical Engineering Department, Marvdasht Branch, Islamic Azad University, Marvdasht, Iran. He is the author of more than 50 journal and conference papers. His teaching and research interests include power system and transformers transients, lightening protection, and optimization methods in power system. 